Iranian Journal of Breast

Diseases. 2022; 14(1):11-20.
Original Article

\section{Predicting the Incidence and Trend of Breast Cancer Using Time Series Analysis for 2007-2016 in Qazvin}

\author{
Hajiabadi $\mathbf{F}^{1}$, Bagheri $\mathbf{H}^{1}$, Tonokaboni $\mathrm{N}^{2}$, Zamanian $\mathbf{M}^{3}$, Hosseinkhani $\mathrm{Z}^{4^{*}}$ \\ ${ }^{1}$ Children Growth Research Center, Research Institute for Prevention of Non- \\ Communicable Diseases, Qazvin University of Medical Sciences, Qazvin, Iran \\ ${ }^{2}$ Non-Communicable Diseases Control Office, Deputy of Health, Qazvin \\ University of Medical Sciences, Qazvin, Iran \\ ${ }^{3}$ Department of Epidemiology and Biostatistics, School of Health, Arak \\ University of Medical Sciences, Arak, Iran \\ ${ }^{4}$ Metabolic Diseases Research Center, Research Institute for Prevention of \\ Non-Communicable Diseases, Qazvin University of Medical Sciences, Qazvin, \\ Iran
}

Receive: $19 / 8 / 2020$

Accepted: 4/2/2021

"Corresponding Author: zhosseinkhani122@gmail.com

Ethics Approval: Not Applicable

\begin{abstract}
Introduction: Breast cancer is the most common cancer and the second leading cause of death in women worldwide. The aim of this study was to analyze the trend and predict the incidence of breast cancer using time series analysis.
\end{abstract}

Methods: In this study, data on breast cancer incidence in Qazvin province between 2007 and 2016 were analyzed using time series analysis with autoregressive integrated moving average (ARIMA) modeling to forecast the future pattern. The Box-Jenkins time series model and its diagnosis and evaluation methods were used to show the trend and forecasting the next year new cancers. To describe and fit the appropriate models, $\mathrm{R}$ statistical software version 3.6.3 was used.

Results: Between 2007 and 2016, a total number of 1229 new patients had been registered (monthly mean [SD]: 10.24 [1.03]). Although the overall trend in the raw number of new breast cancer cases has been increasing over time, the change in observations over time has been increasing and decreasing. According to Bartlett test results, the variances of the data were not constant. Also, according to the results of Kolmogorov-Smirnov test, breast cancer series data were not normal. Among the studied models, ARIMA $(1,1,1)$ was selected due to lower AIC criteria than other models, and this model was selected as the final model for predicting breast cancer for the next year. The confidence interval of the predicted values was relatively narrow, which indicates the appropriateness of the final model in the prediction.

Conclusion: Time series analysis is an efficient tool to model the past and future data on the raw number of new cancer cases, and the goodness-of-fit indicators of the model showed that the Box-Jenkins model is a reliable model for fitting similar data.

Keywords: Breast Cancer, Seasonal Trend, Time Series Analysis, Iran 


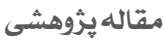

\section{روند و يیشبينى سرى زمانى بروز سرطان بستان در استان قزوين

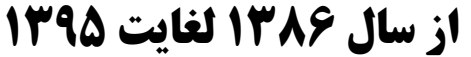

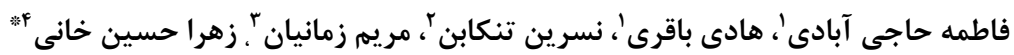 \\ ' مركز تحقيقات رشد كودكان، يزوهشكده يِيشَيرى از بيمارىهاى غير واگير، دانشخاه علوم يزشكى قزوين، \\ قزوين، ايران

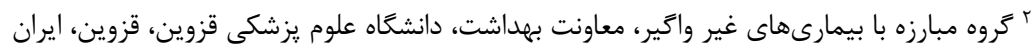

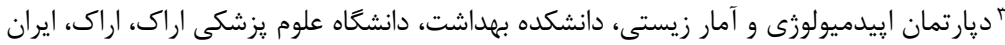

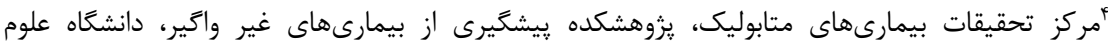 \\ يزشكى قزوين، قزوين، ايران تجميفات بيماري
}

فصلنامه بيمارى هاى يستان ايران

$|\varepsilon \cdot \cdot !| \varepsilon(1): 11-r$.

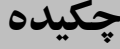

مقدمه: سرطان يستان شايعترين سرطان زنان و دومين علت مرگ در كل جهان مىباشد. مطالعه

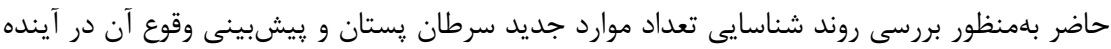
با تحليل سرى زمانى انجام شد.

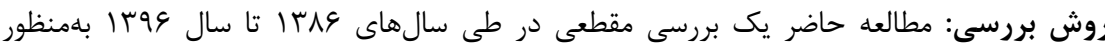

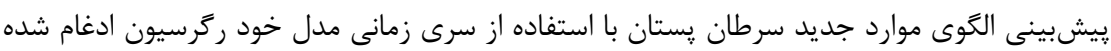

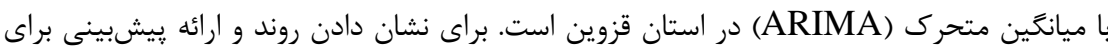

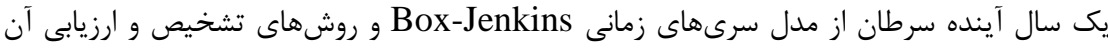

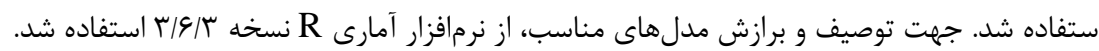

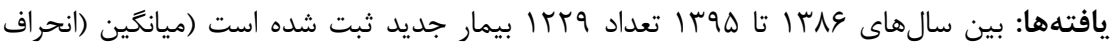

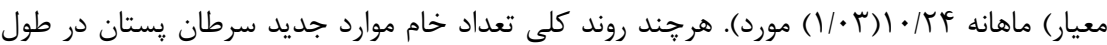

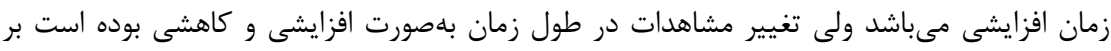

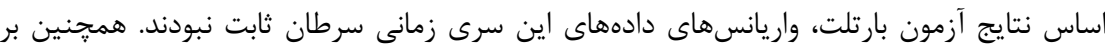

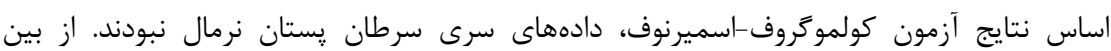

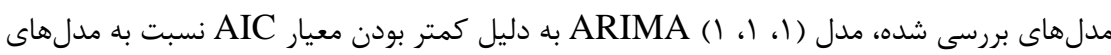

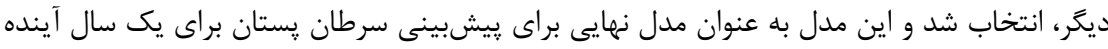

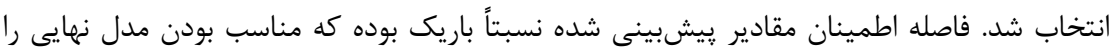
در يِشبينى نشان مى دهد. نتيجهَيرى: تحليل سرى زمانى ابزارى كارا جهت مدلسازى دادهاى كذشته و آينده تعداد خام

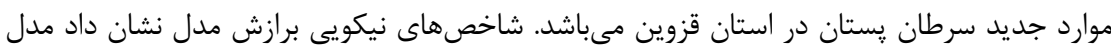

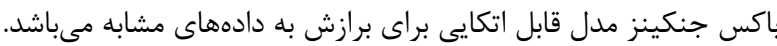
|وازههاى كليدى: سرطان پستان، روند فصلى، تحليل سرى زمانى، ايران

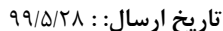

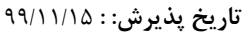

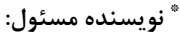
zhosseinkhani122@gmail.com 
ييش بينى روند بروز بيمارى در آينده و اتخاذ اقدامات

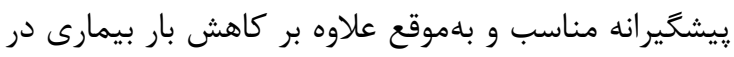

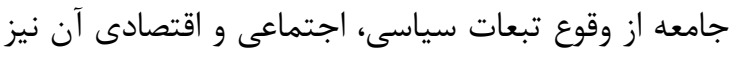
جلوكيرى كرد به همين منظور اين مطالعه با هدف تعيين

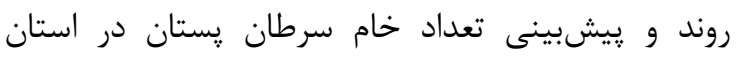

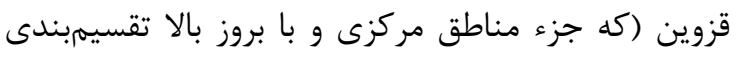

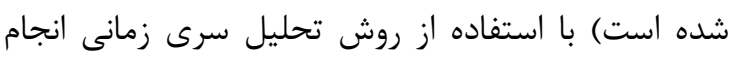

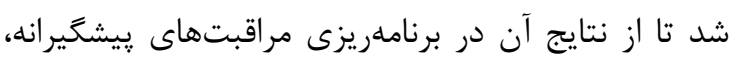
تدوين و اجراى سياستهاى استانى استفاده شود.

\section{مواد و روشها}

در اين مطالعه آمار توصيفى بيماران با جواب تست

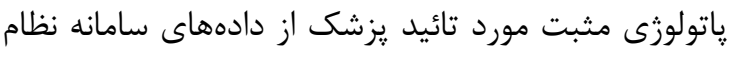

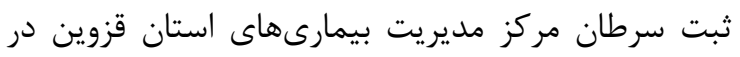

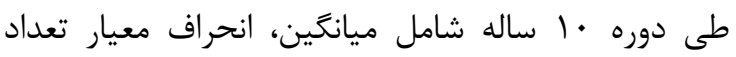
سرطان محاسبه شد. از تحليل سرىهاى زمانى طبق إنى

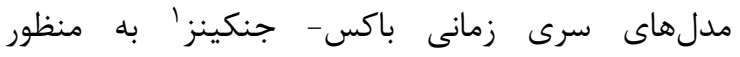

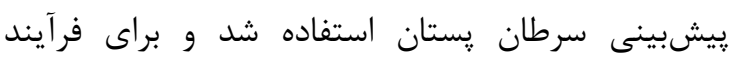
مدلسازى جهت بِيشبينى سه مرحله؛ شناسايى مدل، بران

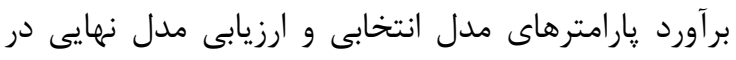

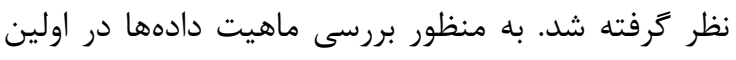

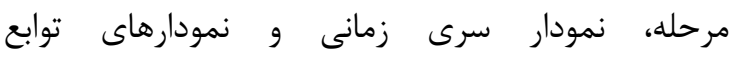

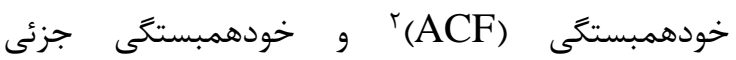
(PACF)

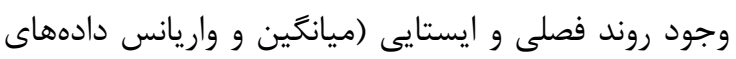

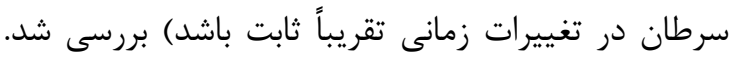

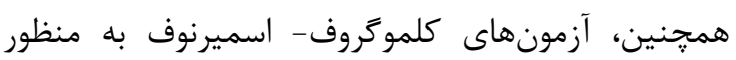

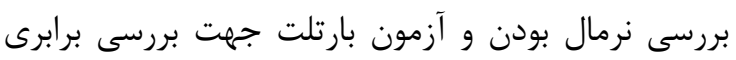

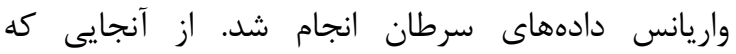

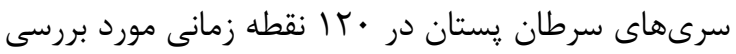

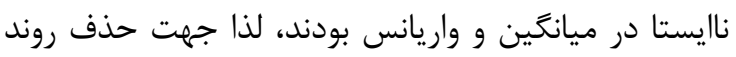

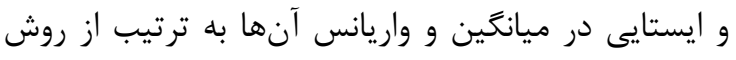
تفاضل

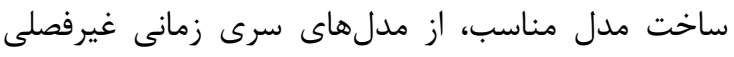
ARIMA

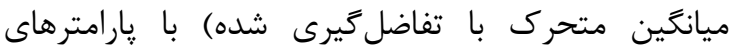

\footnotetext{
${ }^{1}$ Box-Jenkins

${ }^{2}$ Autocorrelation Function

${ }^{3}$ Partial Autocorrelation Function

${ }^{4}$ Box-Cox

${ }^{5}$ Autoregressive Integrated Moving Average
}

سرطان بستان بهعنوان شايعترين سرطان در ميان زنان

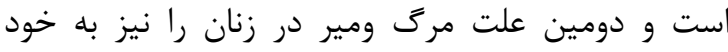

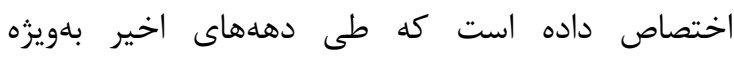
دركشورهاى در حال توسعه و در خانمهاى بالاى •ه سال رشد جشمخيرى داشته است (l، r). اين سرطان عامل دان

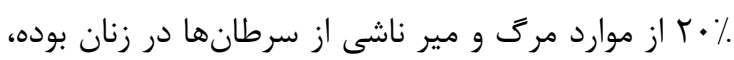

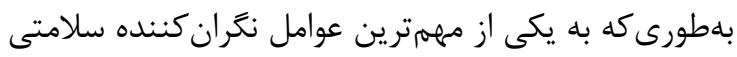

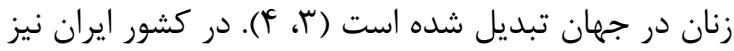

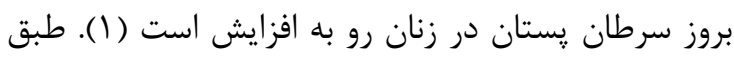
كزارش كشورى برنامه ملى ثبت سرطان در ايران در سال

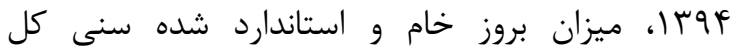
سرطانها در جمعيت زنان، به ترتيب • •

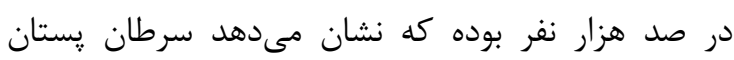
شايعترين سرطان در كل جمعيت زنان كشور مى دباشد

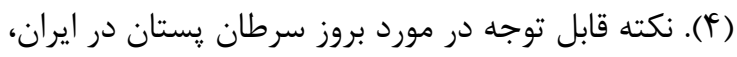

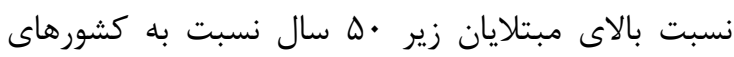

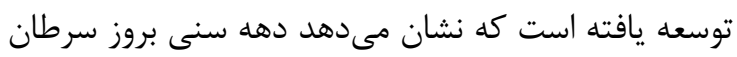

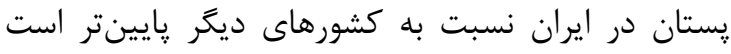
(ه، 9). از ديدگاه إيبدميولوزيكى نيز مطالعات نشان داده دئه

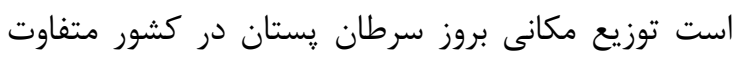

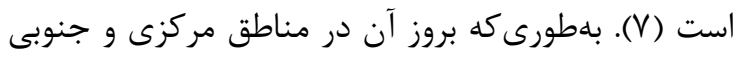
كشور بيشتر ززارش شده است (^). لذا هم ابتلايى سرطان

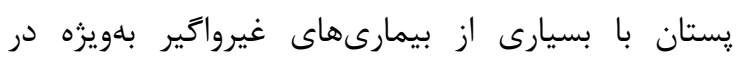

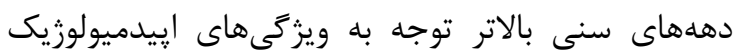

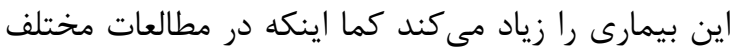

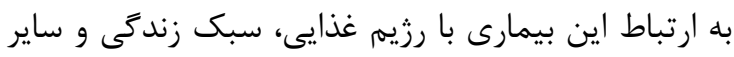

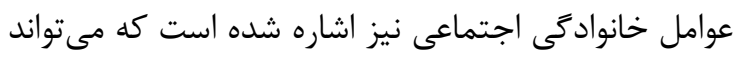

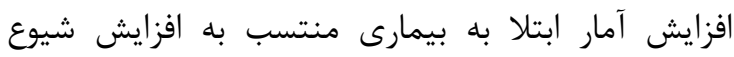

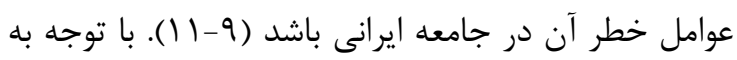

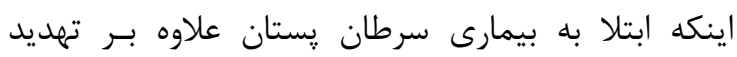

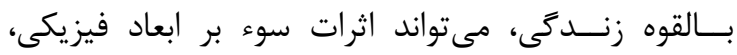

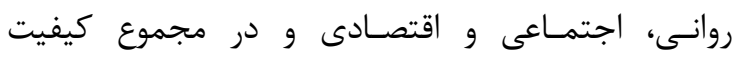

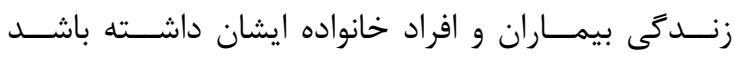

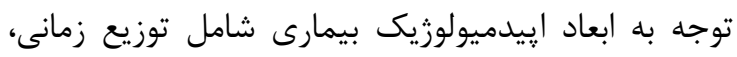

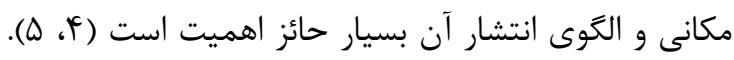

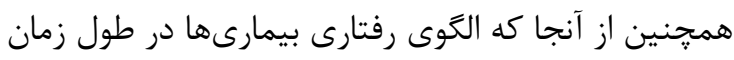

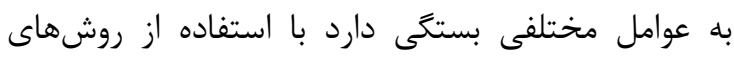
تحليل سرى زمانى و مدلسازى اين الكو مىتوان ضمن باني 


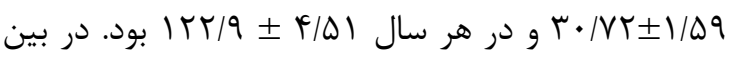

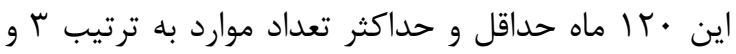

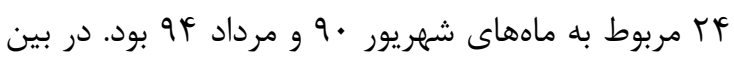

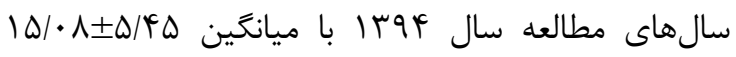

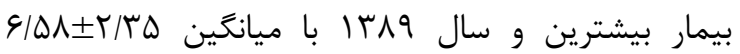
بيمار كمترين بيمار را به خود اختصاص داد. فصل تابستان

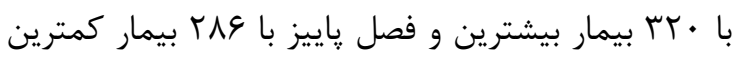

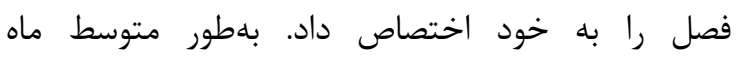
ارديبهشت با · آI بيمار بيشترين، و ماههاى فروردين و

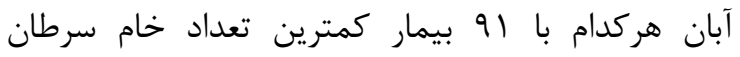

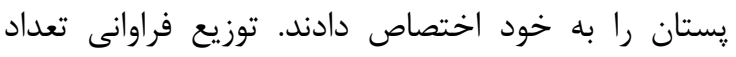

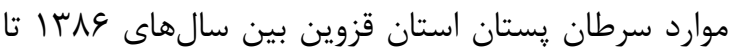
هوץ إ در جدول شماره ا نشان داده شده است. هرجند

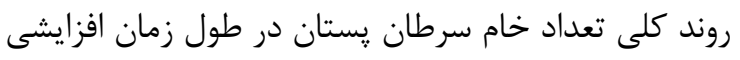

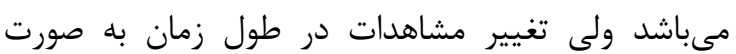
افزايشى و كاهشى بوده است (شكل لاست ().

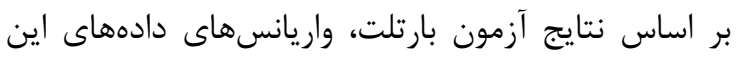

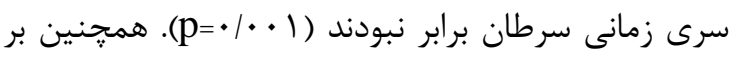

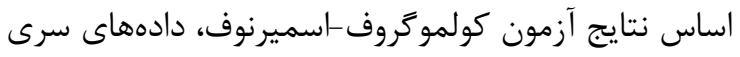

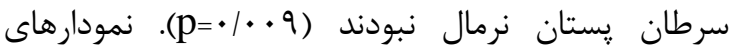
براى دادههاى خام بلهورت زير PACF , ACF

$$
\text { مىباشد (شكل r) }
$$

همجنين نمودارهاى PACF ACF براى دادههاى خام

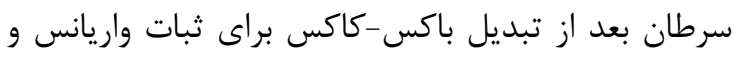
تفاضل گيرى از مرتبه اول بهصورت زير مىباشد (شكل سان).

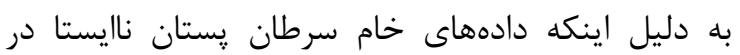

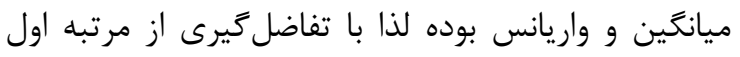

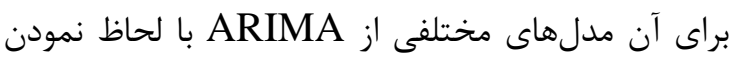
مقادير متفاوتى براى يارامترهاى p و q با اطمينان

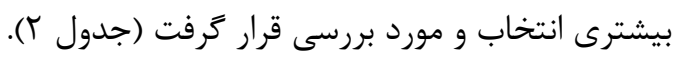

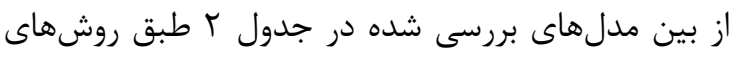

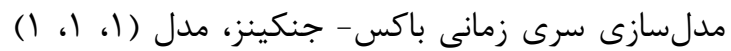
ARIMA

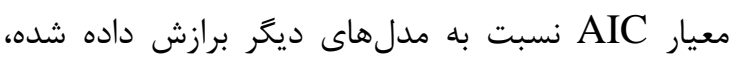

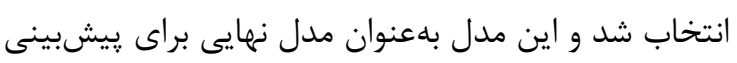

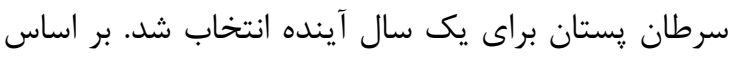

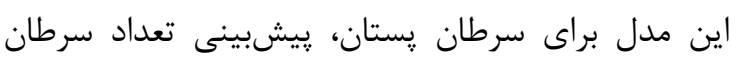

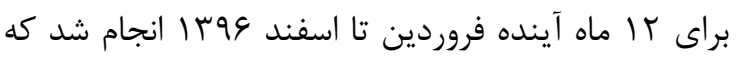

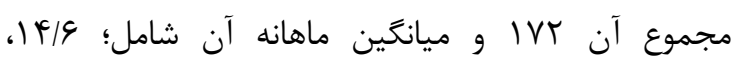

نامعلوم (ضرايب مدل) به عنوان مدل انتخابى استفاده شد.

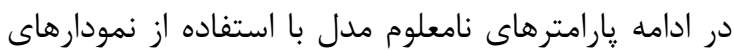
تجبل از تفاضل کيرى، بعد از تفاضل تخمين زده شد. با در نظر كرفتن فاصله اطمينان باقىماندهاى نمودارهاى PACF و ACF مدل بهدست

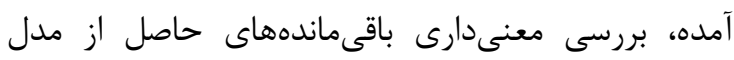

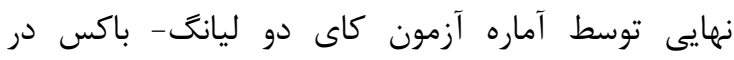
تأخيرهاى زمانى مشخص براى درستى تشخيص يا ارزيابى آنس

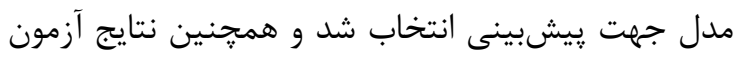

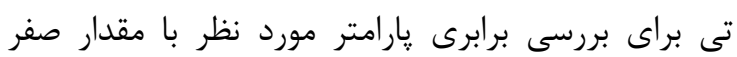

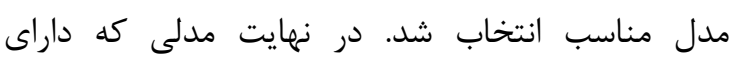
كمترين مقادير محك اطلاع آكائيك (AIC) بود، به ندابه عنوان بهترين مدل انتخاب شد. از بين مدلهاى سرى دالين

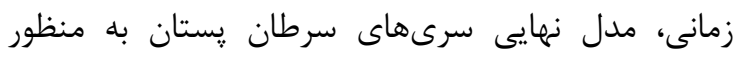

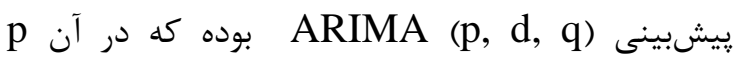

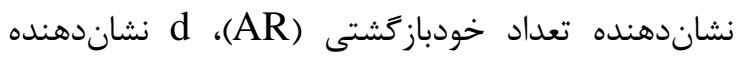

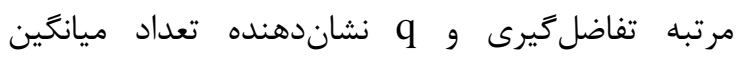
متحرى (MA) در مدلسازى سرى زمانى سرطان يستان مىباشد كه مدل رياضى آن بلصورت زير مىباشد. $\left.j_{p}(B)\right\lrcorner^{d} X_{t}=q_{q}(B) Z_{t}$

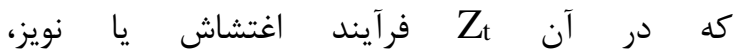
و $\quad f_{p}(B)=1-j_{1} B-\mathrm{L}-j_{p} B^{p}$ $q_{q}(B)=1-q_{1} B-\mathrm{L}-q_{q} B^{q}$

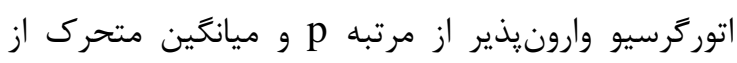
مرتبه q و و ادهرئ

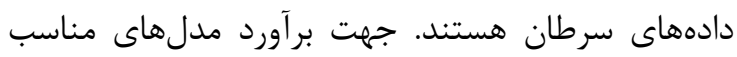

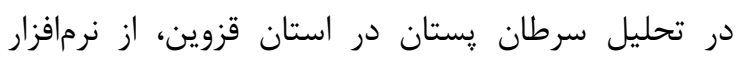

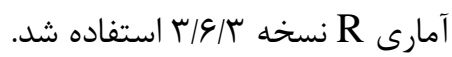

\section{يافتهها}

آمار توصيفى بيماران سرطان پِتان در طى دوره • إلى ساله

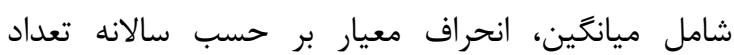

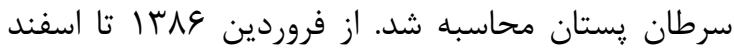

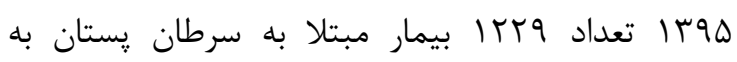
عنوان بخشى از برنامه كنترل بيمارى سرطان در ايران

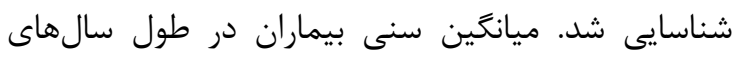

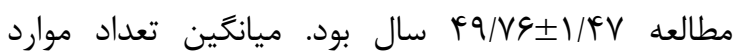
سرطان קستان در هر ماه 
نهايى را در ريشبينى نشان مىدهد. بهطور كلى ميانگين

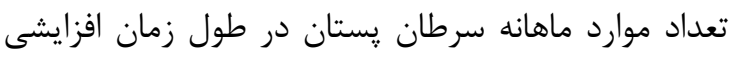

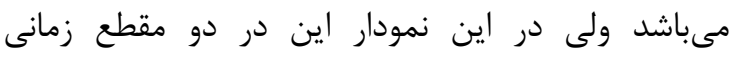

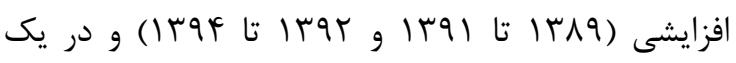

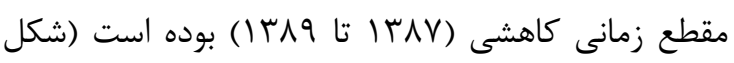

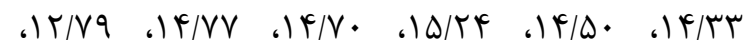
|

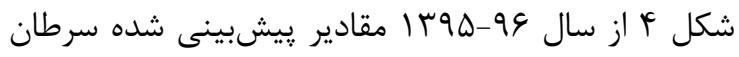

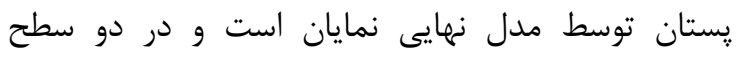

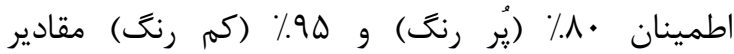

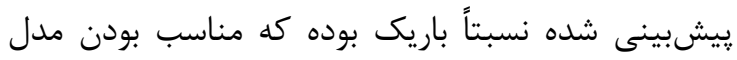

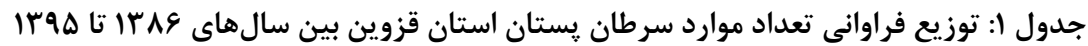

\begin{tabular}{|c|c|c|c|c|c|c|c|c|c|c|c|c|c|}
\hline سال & & زمستا & & & باييز & & & تابست & & & بهار & & \\
\hline 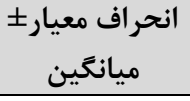 & اسفند & بهمن & دى & آذر & آبان & مهر & شهريور & مرداد & تير & خرداد & ارديبهشت & فروردين & سال \\
\hline $1 / f F \pm V / f 1$ & $\Lambda$ & $\wedge$ & v & 1. & V & $\Lambda$ & 9 & v & $\Lambda$ & $\Delta$ & $\Delta$ & v & IrAs \\
\hline$r|\Lambda| \pm 1 \cdot / \cdot$ & $\Lambda$ & V & 19 & IT & 19 & v & $\wedge$ & f & IT & Ir & 1. & v & IrAv \\
\hline$r / 9 \wedge \pm \wedge / \cdots$ & 4 & $\Delta$ & $\Delta$ & $\wedge$ & r & 4 & 4 & if & 1. & V & V & 9 & $I r \wedge \Lambda$ \\
\hline$r / r \Delta \pm \varepsilon / \Delta \Lambda$ & 9 & 11 & $\Delta$ & 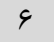 & $\wedge$ & 9 & $\Delta$ & f & f & f & $\wedge$ & 4 & $1 r \wedge 9$ \\
\hline$r / \cdot v \pm q / \cdot$. & 1. & IT & $\Delta$ & 11 & V & 1. & r & if & 11 & V & 9 & 9 & $1 r q$. \\
\hline$\Delta / \cdot \varphi \pm \| / / r \Delta$ & 9 & if & 19 & IT & $\varepsilon$ & 11 & IT & 11 & 11 & 9 & r & i & $\mid r q 1$ \\
\hline$r / 4 \varphi \pm \Lambda / \cdot \Lambda$ & $\Delta$ & 9 & 1. & 11 & f & 1. & $\Delta$ & $\wedge$ & 9 & 11 & 9 & 9 & Irar \\
\hline$r / \cdot 1 \pm 1 r / 19$ & if & IV & 11 & 1. & $1 f$ & IT & 11 & if & if & v & IT & If & Irqu \\
\hline$\Delta / \uparrow \Delta \pm \mid \Delta / \cdot \wedge$ & 9 & TI & IV & 9 & $\Delta$ & 19 & IV & TF & 19 & 10 & IV & IT & Iraf \\
\hline$r / \Lambda \Delta \pm I r / \Lambda \mu$ & TT & 19 & 1. & $\wedge$ & 11 & c & 11 & ז & 11 & 10 & $r$. & 19 & $1 \% 90$ \\
\hline
\end{tabular}

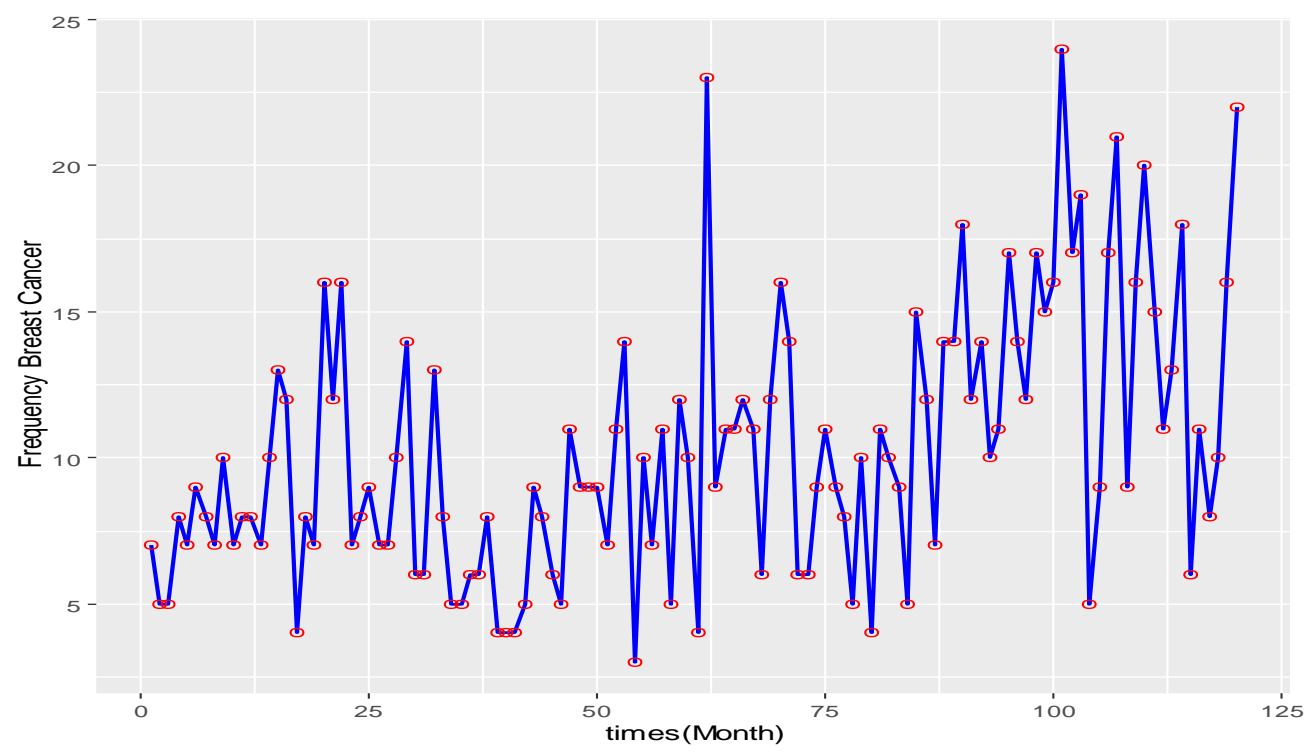

شكل (: سرى زمانى تعداد موارد مشاهده شده سرطان بستان بر حسب ماه 

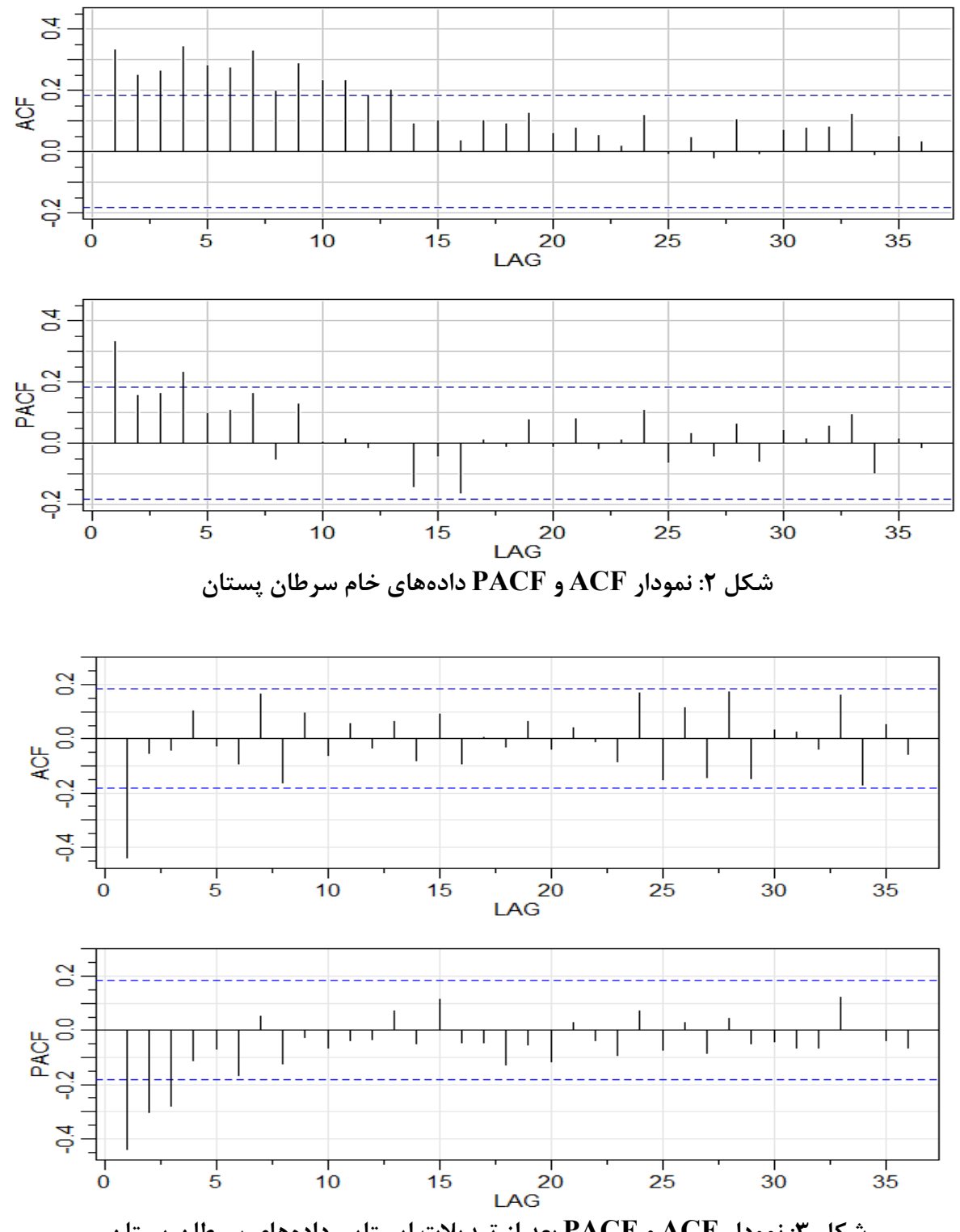

شكل ץ: نمودار ACF و PACF بعد از تبديلات ايستايى دادهاى سرطان يستان

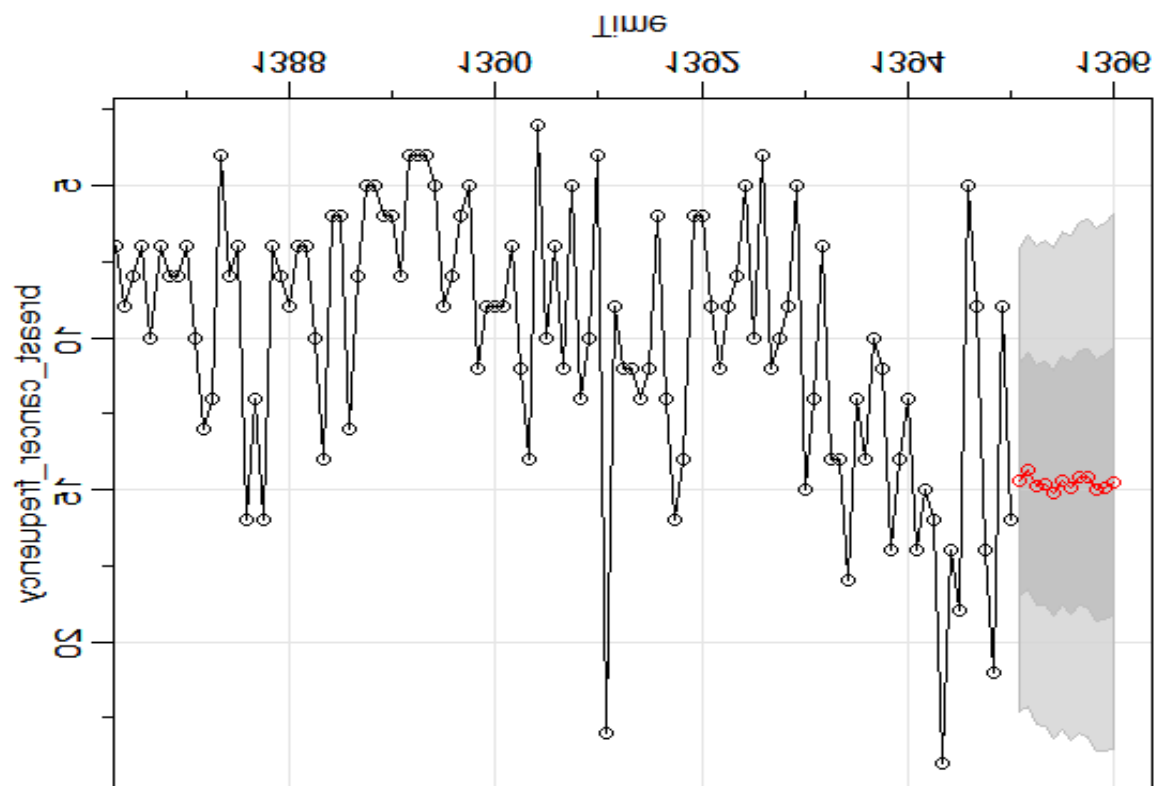

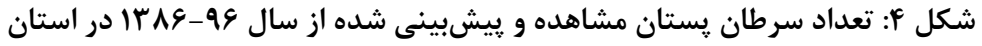




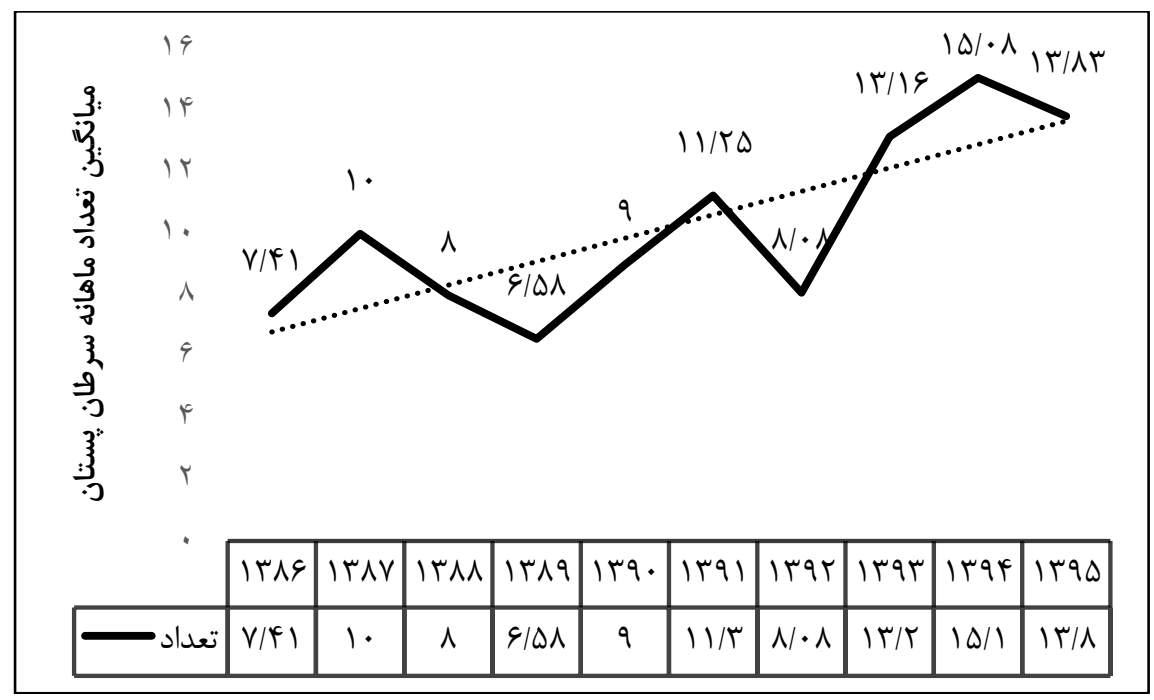

شكل ه: ميانكَين سالانه تعداد موارد سرطان بستان در استان قزوين از سال هو-9^؟|

ֶاتولوزى محور به جمعيت محور تغيير كند و همجنين در

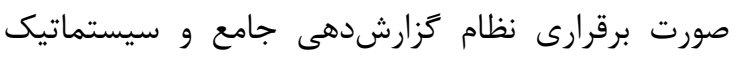

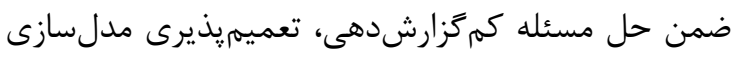

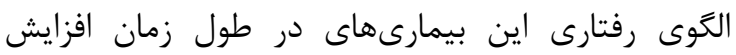

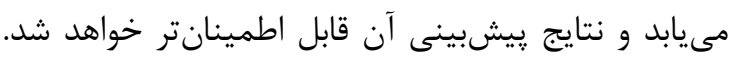

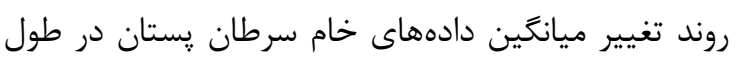
زمان نايستا (نامانا) بود و الكوى فصلى (Seasonality)

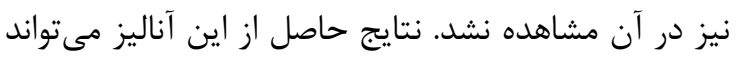

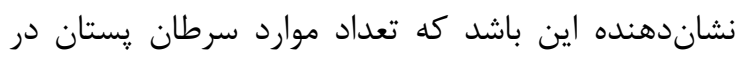

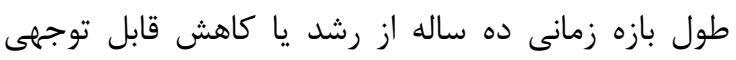

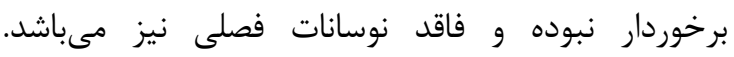
همجنين مدل همردار نبوده

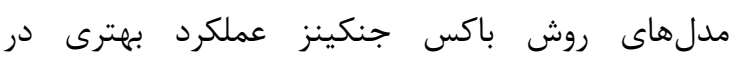

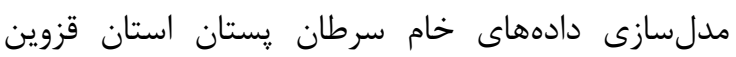
نشان داد. همبستخى زمانى معنى دارى بين يكى داده بان

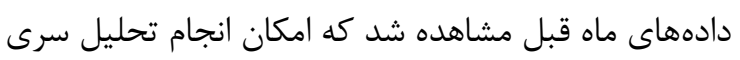

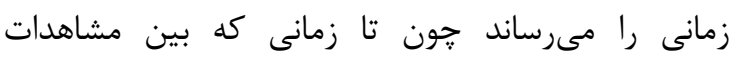

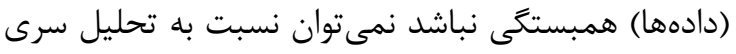

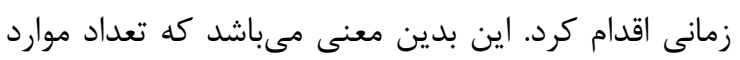
سرطان پستان بر اساس پارامتر زمانى (ماه) داراى تغييرات

$$
\text { معنى دارى بوده است. }
$$

عليرغم اينكه در مطالعه حاضر روند ثابت افزايشى يا

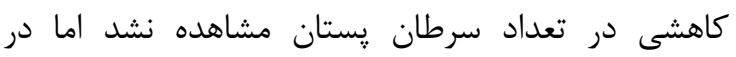

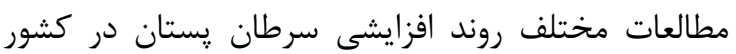

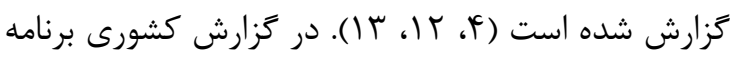

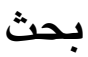

تعيين دقيق و به هنعام وقوع بيش از حد بيمارىها

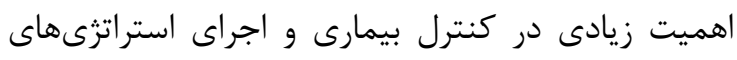

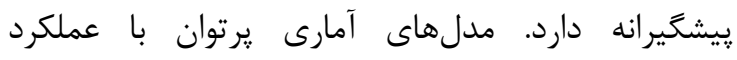

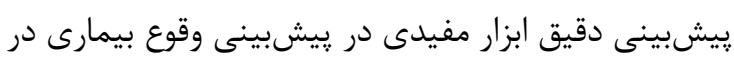
آينده هستند. عملكرد مدل هاى آمارى وابسته به دئ دادههاى دئي

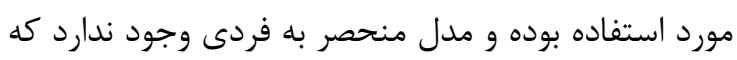

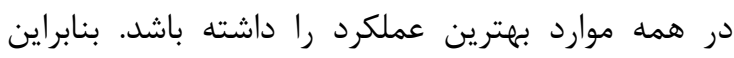

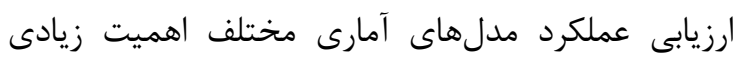

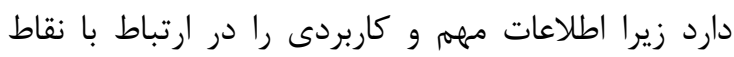

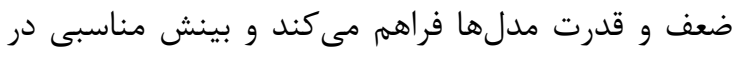

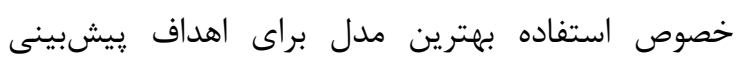

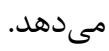
در اين مطالعه سعى شده است با استفاده از تحليل سرى

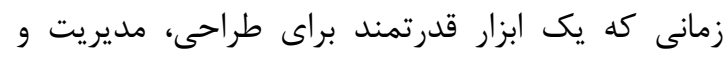

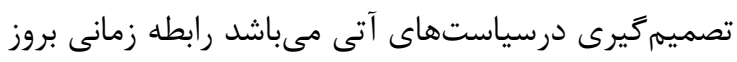

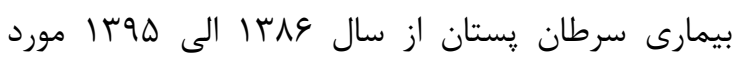

$$
\text { ارزيابى قرار كيرد. }
$$

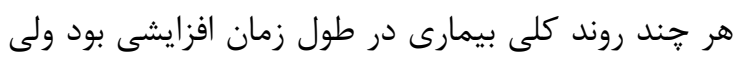

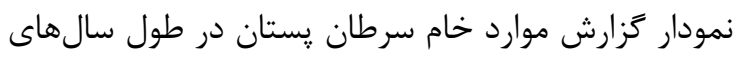

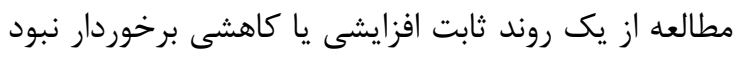

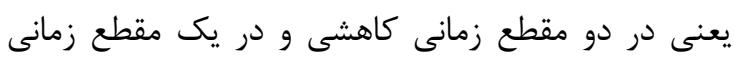

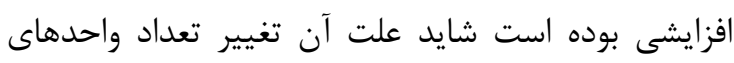
كزارشدهى در طول زمان و نبود يك سيستم جامع و واند

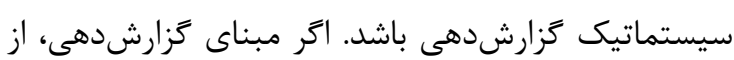




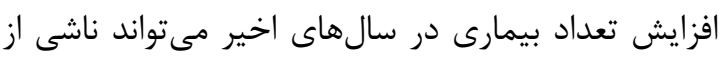

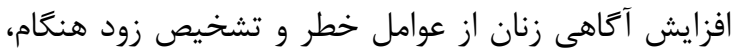
رشد و توسعه شهرنشينى، بالا رفتن سن ازدواج زنان باشد ردان

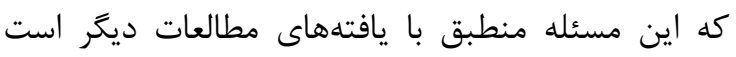
(TY - IN) بيمارى بر خانواده و جامعه نيازمند توجه جدى از جانب

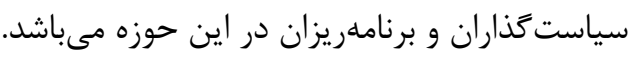

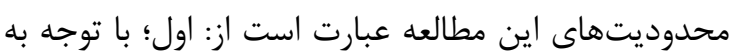
اينكه در اين مطالعه از دادهاى سامانه نظام ثبت سرطان مركز مديريت بيمارىهاى استان قزوين استفاده شده است

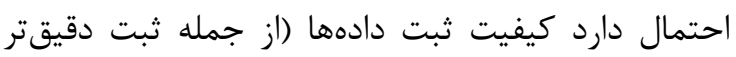

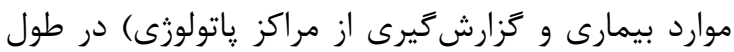
سالهاى مطالعه متفاوت بوده باشد و بر روند ثبت بيمارى

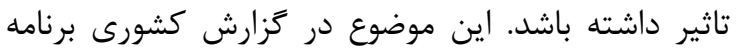

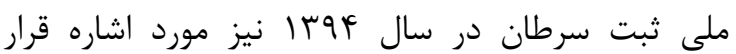
كرفته و عنوان شده است كه كيفيت دادها درا درائ اين كزارش

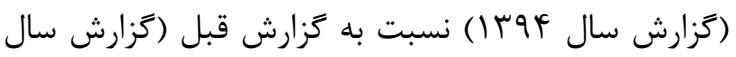

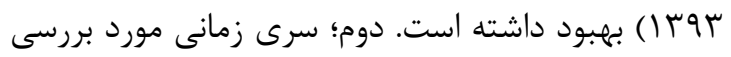
در اين يزوهش فاقد متغيرهاى يُشكو (عوامل تاثير كذار

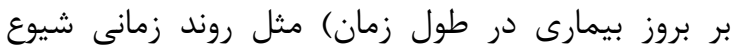

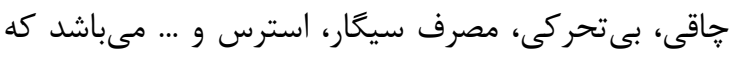

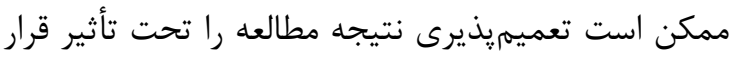
دهد و سوم؛ در اين مطالعه مدل كلاسيك با مدلهاى

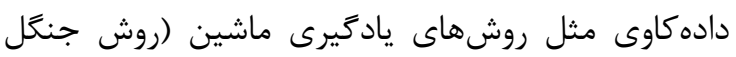

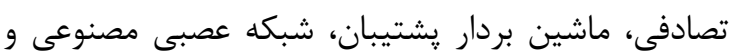
(.... - مقايسه نشده است. از آنجا كه در تحليل سرى زمانى، هدف ايجاد مدلى استى است

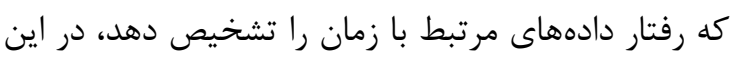

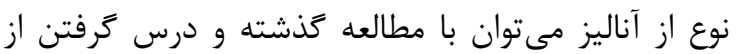

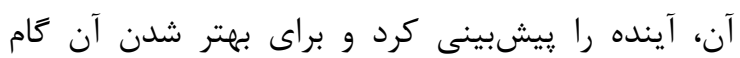

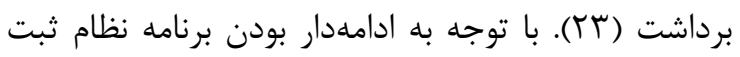

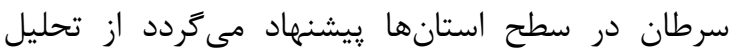
سرى زمانى براى پيشبينى رفتار بيمارى سرطان يستان

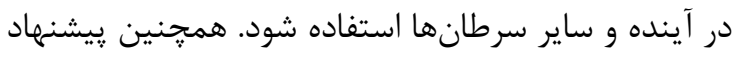

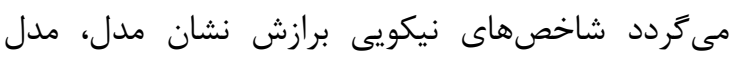
باكس جنكينز مدل قابل اتكايى براى برازش به داد دادههاى

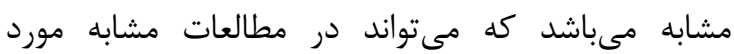

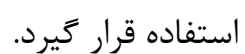

ملى ثبت سرطان كه در سال عqبا از سوى وزارت بهداشت درمان و آموزش يزشكى ايران منتشر كرديد نيز ميزان بروز خام افزايش داشته است. در اين كزارش ميزان

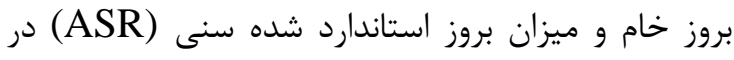

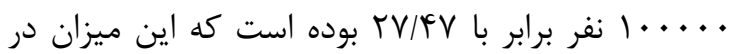

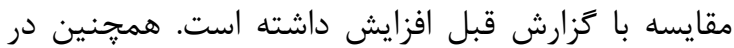

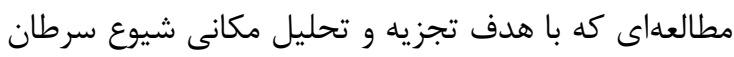

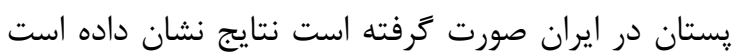
بيشترين ميزان شيوع مربوط به استانهاى مركزى كشور

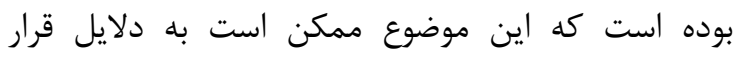

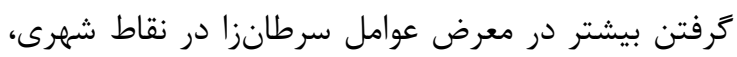
شيوه زندگى غربى و شيوع بالاتر عوامل خطر باشد (I (l).

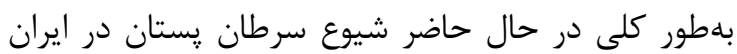
عليرغم يايينتر بودن نسبت به بسيارى از كشورهاى

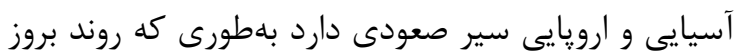
در همه مناطق جغرافيايى ايران افزايش يافته است و واسئ همجنين مقايسه نتايج يزوهش حاضر براى مناطق مختلف

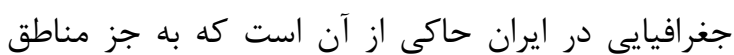

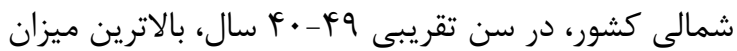
سرطان קستان در ساير مناطق كشور مشاهده مى شود

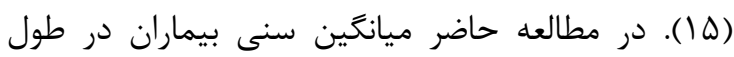

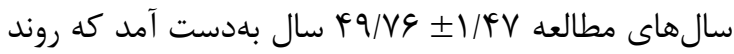
افزايشى داشته است. ميانخين سنى بيماران مبتلا در طى لى

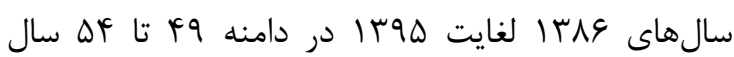
بوده است. در مطالعات مختلف انجام شده در جامعه ايرانى

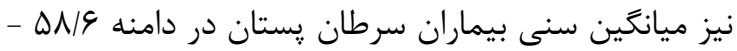
1/ ه كزارش شده است كه نشان مىدهد كه در ايران

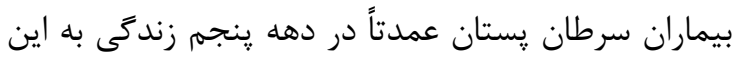

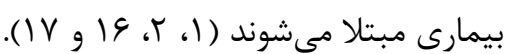

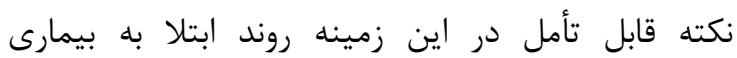

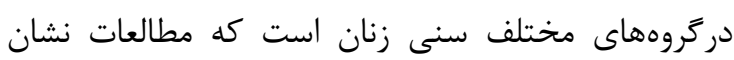
داده است سن ابتلا به سرطان يستان در جان جامعه ايرانى

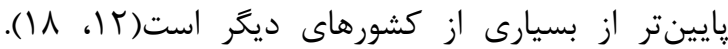

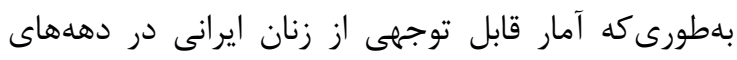

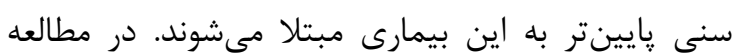
ديخرى كه در شمال ايران انجام شد روند افزايشى قابل بيل دئل توجهى در بروز بيمارى در كروههاى مختلف سنى اندام مشاهده

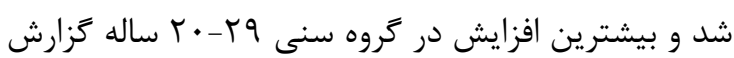

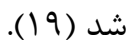


يستان نشان داد. همبستكى زمانى معنىدارى بين يك

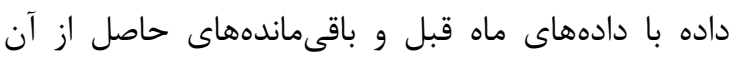
وجود داشت.

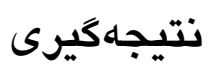

بهدليل الكوى غيرفصلى تعداد موارد سرطان يستان در

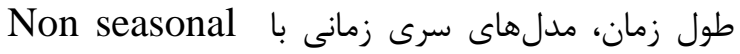
ARIMA

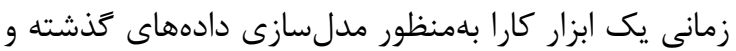

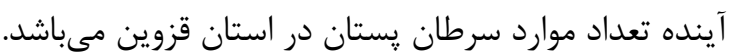

$$
\begin{aligned}
& \text { تعارض منافع } \\
& \text { نويسند } \\
& \text { يزوهش حاضر وجود ندارد. }
\end{aligned}
$$

\section{References}

1. Zaidi Z, Dib HA. The worldwide female breast cancer incidence and survival, 2018, Epidemiology, American Association for Cancer Research, 2019, https://doi.org/10.1158/1538-7445. AM20194191.

2. Goossensen A, Somsen J, Scott R, Pelttari L. Defining volunteering in hospice and palliative care in Europe: an EAPC White Paper. European journal of palliative care. 2016; 23(4):184-91.

3. Yavari P, Mosavizadeh M, Khodabakhshi R, Madani H, Mehrabi Y. Reproductive characteristics and the risk of breast cancer: a case-control study. Iranian Journal of Epidemiology. 2006; 1(3):11-9.

4. Jazayeri SB, Saadat S, Ramezani R, Kaviani A. Incidence of primary breast cancer in Iran: Ten-year national cancer registry data report. Cancer epidemiology. 2015; 39(4):519-27.

5. Asgarian F, Mirzaei M, Asgarian S, Jazayeri M. Epidemiology of breast cancer and the age distribution of patients over a period of ten years. Iranian Quarterly Journal of Breast Disease. 2016; 9(1):31-6.

6. Fares MY, Salhab HA, Khachfe HH, Khachfe HM. Breast cancer epidemiology among

$$
\begin{aligned}
& \text { بهطور كلى نتايج اين بيشبينى نشان داد روند كاهشى كه }
\end{aligned}
$$

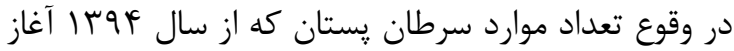

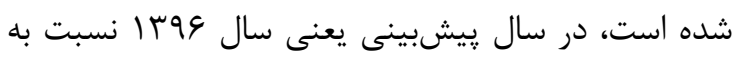

$$
\begin{aligned}
& \text { سال ه9 با تفاوت جندانى نداشته باشد و در مر ماههاى سال }
\end{aligned}
$$

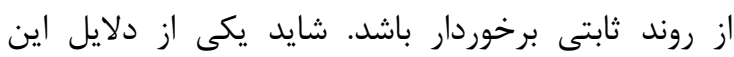

$$
\begin{aligned}
& \text { موضوع عدم اتخاذ اقدام كنترلى تاثيرگذار بر روند وقوع } \\
& \text { بيمارى و عدم تغيير در نظام تشخيص، درمان و مراقبت }
\end{aligned}
$$

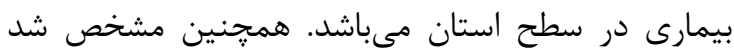

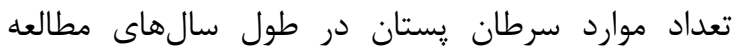

$$
\begin{aligned}
& \text { (19 تا ه9) در دو مقطع زمانى افزايش و در دو مقطع } \\
& \text { زمانى كاهش يافته است. آناليز سرى زمانى در اين مطالعه داني }
\end{aligned}
$$

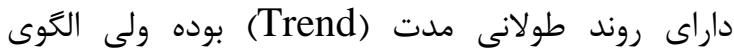

$$
\begin{aligned}
& \text { فصلى (Seasonality) از خود ران نشان ندان (1) نداد. مدل } \\
& \text { ARIMA }(1,1,1) \\
& \text { دسته عملكرد بهترى در مدلسازى داده هاى خام سرطان }
\end{aligned}
$$

Lebanese women: an 11-year analysis. Medicina. 2019; 55(8):463.

7. Abbastabar H, Soleymani DM, Hamidi FP, Jalilian F, Mirzaee AM, Nasir ZM. The relationship between breast cancer and the most common noncontagious disease risk factors: an ecologic study. J Health Syst Res. 2012; 8:369-76.

8. Alsolami FJ, Azzeh FS, Ghafouri KJ, Ghaith MM, Almaimani RA, Almasmoum HA, et al. Determinants of breast cancer in Saudi women from Makkah region: a case-control study (breast cancer risk factors among Saudi women). BMC public health. 2019; 19(1): 1554.

9. Molaei-Zardanjani M, Savabi-Esfahani M, Taleghani F. Fatalism in breast cancer and performing mammography on women with or without a family history of breast cancer. BMC women's health. 2019; 19(1):1-5.

10. Albert U-S, Koller M, Wagner U, Schulz K-D. Survival chances and psychological aspects of quality of life in patients with localized early stage breast cancer. Inflammation Research. 2004; 53(2):S136-S41.

11. Ramezani R. Iranian annual of national cancer registration report. Tehran: Tandis. 2007:1156. 
12. Fazel A, Hasanpour-Heidari S, Salamat F, Rajaie S, Kazeminezhad V, Naeimi-Tabiei M, et al. Marked increase in breast cancer incidence in young women: A 10-year study from Northern Iran, 2004- 2013. Cancer epidemiology. 2019; 62:101573.

13. Mahdavifar N, Pakzad R, Ghoncheh M, Pakzad I, Moudi A, Salehiniya H. Spatial analysis of breast cancer incidence in Iran. Asian Pacific Journal of Cancer Prevention. 2016; 17:59-64.

14. Nafissi N, Saghafinia M, Motamedi MHK, Akbari ME. A survey of breast cancer knowledge and attitude in Iranian women. Journal of cancer research and therapeutics. 2012; 8(1):46.

15. Banegas MP, Bird Y, Moraros J, King S, Prapsiri S, Thompson B. Breast cancer knowledge, attitudes, and early detection practices in United States-Mexico border Latinas. Journal of Women's Health. 2012; 21(1):101-7.

16. Nasrollahzadeh M, Delshad MSE, MansourGhanaei R, Maleki Z, Joukar F, Hassanipour $\mathrm{S}$, et al. The prevalence, epidemiology and screening results of breast cancer in women of Guilan province, north of Iran: A crosssectional study during 2017-2018. Clinical Epidemiology and Global Health. 2020; doi:10.1016/j.cegh.2020.03.013

17. Janbabaee G, Moosazadeh M, Asdaghi Jahrom Z. Epidemiological, clinical and pathological characteristics of patients with breast cancer. Journal of Mazandaran
University of Medical Sciences. 2016; 25(134):43-51.

18. Ghoncheh M, Mahdavifar N, Darvishi E, Salehiniya H. Epidemiology, incidence and mortality of breast cancer in Asia. Asian Pacific journal of cancer prevention. 2016; 17(S3):47-52.

19. Abachizadeh K, Moradi-Kouchi A, GhanbariMotlagh A, Kousha A, Shekarriz-Foumani R, Erfani A. Breast cancer in Iran: Levels, variations and correlates. Community Health (Salāmat-i ijtimā̄i). 2018; 5(1):11-21.

20. Qelichi MM, Murgante B, Feshki MY, Zarghamfard M. Urbanization patterns in Iran visualized through spatial auto-correlation analysis. Spatial Information Research. 2017; 25(5):627-33.

21. Nikpour M, Hajian-Tilaki K, Bakhtiari A. Risk Assessment for Breast Cancer Development and Its Clinical Impact on Screening Performance in Iranian Women. Cancer Management and Research. 2019; 11: 10073.

22. Torabi F, Baschieri A. Ethnic differences in transition to first marriage in Iran: The role of marriage market, women's socio-economic status, and process of development. Demographic Research. 2010; 22:29-62.

23. Mills, T. C., \& Lutkepohl, H. (1993). Introduction to Multiple Time Series Analysis. Journal of the Royal Statistical Society. Series A (Statistics in Society); 156(2): 325. doi:10.2307/2982748 